\title{
SEISMIC RESPONSE OF REACTIVE POWDER CONCRETE COLUMNS CONFINED WITH FRP
}

\author{
Muhammad ABBASSI ${ }^{1 *}$, Hooshang DABBAGH ${ }^{1}$
}

\begin{abstract}
In this research, which is based on the finite element method, the behavior of reactive powder concrete (RPC) columns confined with fiber-reinforced polymer (FRP) under seismic excitation is investigated. The governing theory in the numerical simulation is based on the fiber finite element method. The adequacy of the fiber model in predicting the response of FRP-confined RPC columns is validated through comparisons with the available experimental results. To study the seismic behavior of FRP-confined RPC columns, the fiber model presented was subjected to different earthquakes. In this regard, four ground acceleration time histories with different peak accelerations were applied to investigate the response of FRP-confined RPC columns. The results show that reactive powder concrete columns confined with FRP exhibit an acceptable seismic performance. The investigation also confirms that RPC-confined columns show a high degree of ductility. Additionally, the load capacity (maximum lateral load) is increased, and the concrete's compressive strength is increased.
\end{abstract}

\author{
Address \\ 1 Dept. of Civil Engineering, University of Kurdistan, \\ Sanandaj, Iran \\ * Corresponding author: abasi.muhammad@gmail.com
}

\section{Key words}

- Finite element method;

- Reactive powder concrete column;

- Seismic response;

- Compressive strength;

- Modelling;

- FRP.

\section{INTRODUCTION}

Fiber-reinforced polymer (FRP) composite structures are finding broader acceptance from end users through a wider range of applications in civil infrastructure as an alternate to conventional concrete, steel, and timber structures (Gangrao et al., 2007). The behavior of normal/high strength concrete columns confined with FRP under an axial loading is widely recognized and has been the subject of numerous experimental investigations. In this context, numerous experimental research studies have determined that external confinement by means of FRP wrapping highly increases the strength and ductility of concrete columns (Ma and Xiao, 1999; Bouchelaghem et al., 2011; El-Hacha and Abdelrahman, 2013). In the field of FRP-confined concrete columns under seismic loading, only a few authors have evaluated the behavior of these columns subjected to seismic actions.

In this regard, the seismic response of reinforced concrete (RC) columns retrofitted with FRP have been studied (Xiao, 1997; Purba and Mufti, 1999). The researchers concluded that the seismic performance of RC columns are improved and demonstrate increased ductility with their confinement by FRP. Additionally, an analytical model that takes into consideration the bond-slip deterioration of lapspliced longitudinal bars has been developed for seismic assessment and retrofit design (Xiao, 1997).

The use of stay-in-place FRP formwork as a concrete confinement reinforcement for high and normal strength concrete columns with circular cross sections has been investigated (Ozbakkaloglu and Saatcioglu, 2006). Large-scale specimens with different concrete strengths have been experimentally tested under a constant axial compression load and incrementally increasing lateral deformation reversals (Ozbakkaloglu and Saatcioglu, 2006). It was concluded that the inelastic deformability of high and normal strength concrete columns can be improved significantly by using FRP tubes that go beyond the performance level usually expected of comparable columns confined with conventional steel reinforcements. 
Ye et al. (2003) experimentally tested RC columns strengthened with FRP under a constant axial load and lateral cyclic load in order to determine the effects of FRP reinforcement systems on them. Specimens, including two strengthened after being loaded to yield level to imitate strengthening with some damage and one strengthened under a sustained axial load to imitate strengthening under service conditions, were investigated. The enhancement of ductility with the confinement of the FRP sheets was studied according to the development of strains and their distribution in the FRP sheets. Based on the experimental results, a confinement factor for the FRP and an equivalent transversal reinforcement index were suggested.

As has been shown by this brief review of the literature, although the seismic response of normal/high strength concrete columns confined with FRP have been studied, evaluating the seismic behavior of reactive powder concrete columns confined with fiber-reinforced polymer is still a challenging issue. In this context, an area where the use of FRP has attracted considerable interest is in the confinement of reactive powder concrete (RPC) columns. Reactive powder concrete has been used in many application fields of the construction industry, such as civil engineering, mining engineering, and military works for the last two decades (Morin et al., 2002; Dowd et al., 1999). Compared to normal strength concrete (NSC), RPC has ultra-high compressive strength, limited shrinkage and a high degree of toughness. By taking advantage of the ultra-high compressive strength of RPC, the cross-sectional dimensions of columns for newer high-rise buildings can usually be reduced, so that one can get more space to use and to rent (Aïtcin, 2000; Lee, 2002; Ho et al., 2010). In this context, since reactive powder concrete is poor in tension and ductility, a column without any form of reinforcement will fail when subjected to cyclic loads and/or a relatively small tensile load. In this regard, the use of FRP to strengthen the concrete is an effective solution to increase the overall strength of a structure (Abdelouahed, 2006).

One of the techniques used to estimate the behavior of confined concrete columns is the utilization of the finite element method. In the numerical approach field, several studies have been conducted to study the behavior of FRP-confined concrete columns (Jiang and Wu, 2012; Yu et al., 2010; Abbassi and Dabbagh, 2014). It is notable that most of the previous research has been about predicting the response of normal and high-strength concrete columns under an axial compressive load with different eccentricities so that the behavior of RPC columns confined with FRP is not obvious. On the other hand, confining reactive powder concrete columns with FRP requires further studies. Therefore, this paper presents and discusses the results obtained from a finite element analysis of reactive powder concrete columns confined with FRP under seismic loading. In this regard, in the first phase, a numerical study based on the fiber finite element method was conducted to predict the behavior of a FRP-confined RPC column. In order to check the validity and reliability of the fiber model, the numerical results were compared with the available experimental data. In the second phase, using the fiber model presented, finite element analyses were carried out to investigate the seismic response of full scale reactive powder concrete columns confined with FRP.

\section{FIBER FINITE ELEMENT METHOD}

The finite element modeling approach used in this paper is based on the fiber finite element methodology (Feng and $\mathrm{Xu}$, 2018; Jiang and Usmani, 2018; Spacone et al., 1996; Guidi, 2011). The fiber model has been recognized as one of the best-known methods for static and dynamic analyses of frames and RC elements. In general with finite element continuum models, the most important aspects of fiber element models are that they require a significantly reduced number of degrees of freedom and user-defined constitutive parameters. Moreover, the analysis time of fiber finite element models is decreased in comparison with analyses performed using a micro-element approach. The fiber element approach could be defined as a hy-

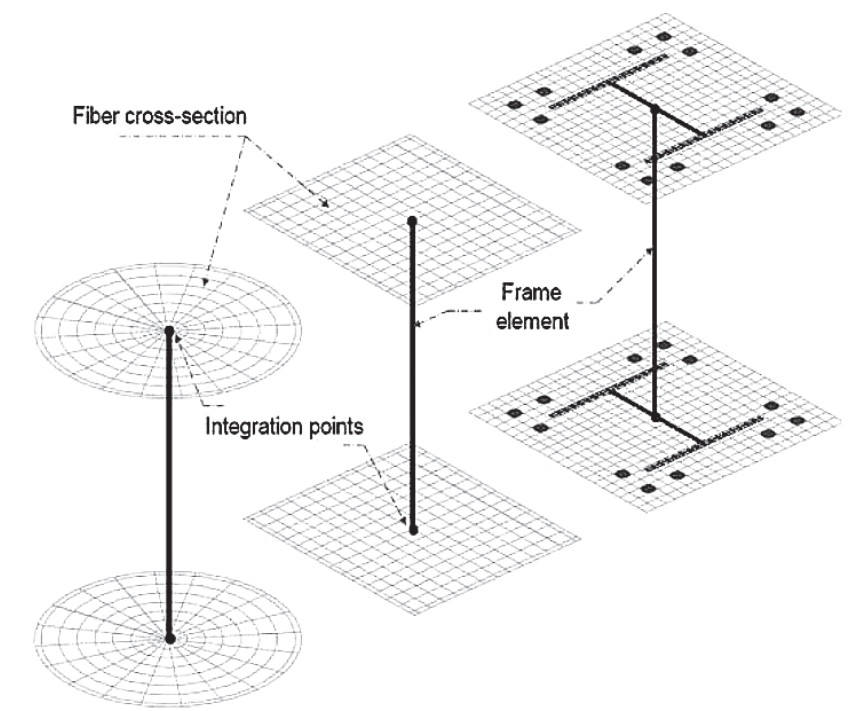

Fig. 1 Frame element with ends coupled to the fiber cross-sections

brid between finite element models (micro models) and macro-models (Guidi, 2011).

Fiber element analysis is a numerical technique that models a structural element by dividing it into a number of two-end frame elements and by linking each boundary to a discrete cross-section with a fiber grid (Fig. 1). In this model, there are a number of control cross-sections along the element. These sections are located at the control points of the numerical integration scheme. The characteristics of the element, such as the element displacement and element forces, are derived from integrating their sectional components along the element. The corresponding sectional components, such as the section forces, are calculated from the integration of the response of the fibers.

The material stress-strain response in each fiber is integrated to get the stress-resultant forces and rigidity terms; the forces and rigidities over the length of the fiber are obtained from these through finite element interpolation functions that must satisfy equilibrium and compatibility conditions. The formulation of the fiber finite element model is based on an assumption of linear geometry. The sections remain plane and normal to the longitudinal axis.

In this research, a two-noded nonlinear beam-column element is used to model the FRP-confined RPC columns. The nonlinear beam-column element has distributed nonlinearity and three degrees of freedom at each node. The finite element model used in this paper considers the FRP-confined RPC columns to be replaced at their centroid axis by a nonlinear beam-column element. The number of nodes for seismically loaded FRP-confined RPC columns is two, and the number of elements is one. Fig. 2 shows a typical fiber model for the numerical analysis. For simplicity, the following assumptions have been adopted in the present study:

1) The modeling approach described was originally developed for FRP wrapping-confined RPC columns with circular cross sections. 2) A perfect bond is assumed between the concrete and FRP so that any slippage of the FRP wrapping is ignored. 3) The geometric interaction between the FRP wrapping and the reactive powder concrete is ignored in the modeling. 4) The norm displacement increment is considered to be $1 \mathrm{e}-5$ for the evaluation of the convergence.

In this paper, the cross-section of the FRP-confined RPC columns is divided into two parts, which include the reactive powder concrete and fiber-reinforced polymer. Each of the two parts is discretized into several discrete and smaller cross-section regions (fibers) in the circumferential and radial directions. The stress-strain model of the FRP and RPC is required to describe the behavior of each of the two parts (fibers). The response of the confined RPC columns is derived by the integration of the constitutive stress-strain behavior of the fibers. 


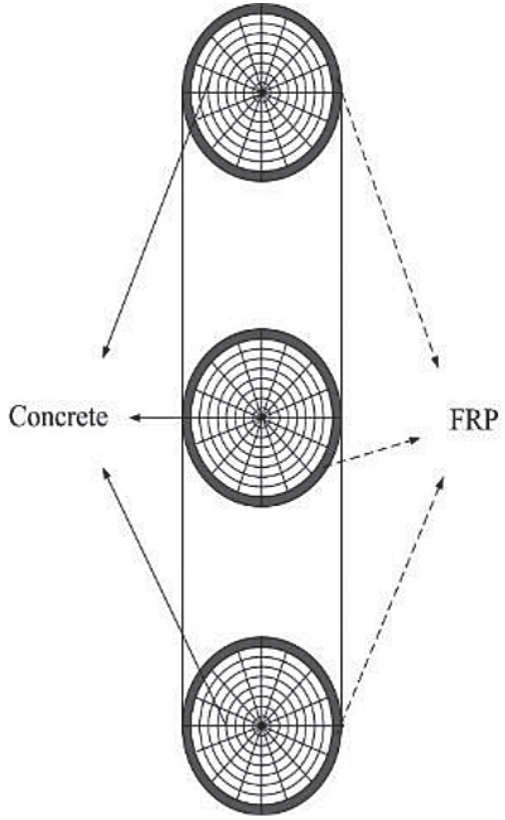

Fig. 2 Schematic of the partition of the monitored cross-section of the FRP-confined RPC columns into fibers

Additionally, the nonlinear behavior of the beam-column element at each cross section level derives entirely from the resultant stressstrain response of the fibers. A finite element model of the FRP-confined RPC columns was built using the open system for earthquake engineering simulation software (OpenSees) (Mazzonni et al., 2007).

\section{MATERIAL LAWS}

On the basis of a number of studies on a constitutive model of concrete in compression, a modified Kent and Park model was used to define the compression behavior of RPC (Abbassi and Dabbagh, 2014; Abbassi, 2012). The modified Kent and Park model includes three regions: a parabolic ascending stress region, a linear descending region, and a constant residual stress region, a typical curve of which is shown in Fig. 3.

Where the maximum compressive strength of RPC is $f_{m}^{\prime}, \stackrel{a}{a}_{m}$ denotes the corresponding strain at the maximum compressive strength; $f_{u}$ is the ultimate compressive strength of the RPC; $\stackrel{a}{u}_{u}$ is the corresponding strain at the ultimate compressive strength; and $E_{C}$ is the modulus of elasticity.

Based on a number of tests and research on concrete (Yalcin and Saatcioglu, 2000; Coronado and Lopez, 2006; Al-Amery and Al-Mahaidi, 2006), it is assumed that a constitutive model for describing the stress-strain behavior of RPC in tension comprises an ascending linear elastic portion up to the tensile strength $f_{t}^{\prime}$; a descending linear portion that accounts for tension stiffening occurs after this point. The typical stress-strain behavior of reactive powder concrete in tension is shown in Fig. 4.

Where $E_{t s}$ is the tension-softening stiffness (slope of the linear tension-softening branch), $f_{t}^{\prime}$ and $a_{t}$ are the tensile strength and corresponding strain at the tensile strength, respectively.

For FRP, it is assumed that the FRP constitutive model in tension and compression is linear, elastic, and brittle. Additionally, the FRP possesses the same elastic modulus in tension and compression (AlAmery and Al-Mahaidi, 2006). The typical stress-strain behavior of FRP is plotted in Fig. 5.

In Fig. 5, $E_{f r p}$ is the modulus of elasticity of FRP, and $\stackrel{\circ}{a}_{t \max }$ and $\stackrel{\circ}{c}_{c_{\max }}$ are the maximum compressive strains in tension and compression, respectively.

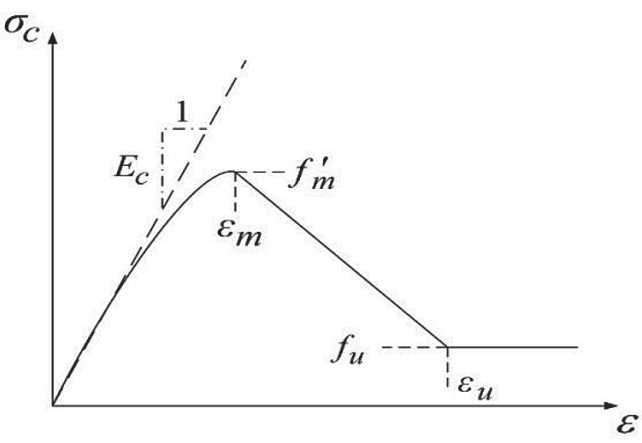

Fig. 3 Typical constitutive model of concrete in compression

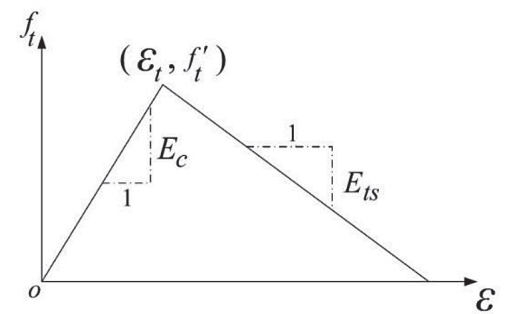

Fig. 4 Typical concrete constitutive model in tension

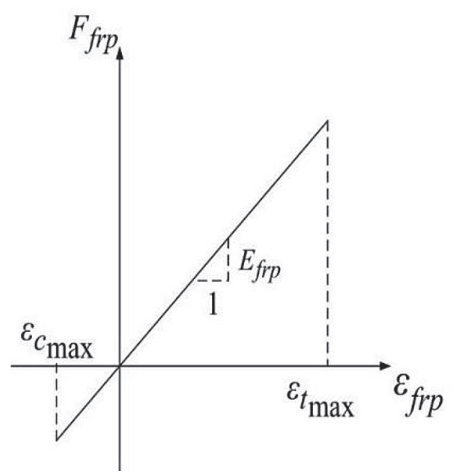

Fig. 5 Typical FRP constitutive model

\section{EXAMPLES OF THE MODEL'S VALIDATION}

Usually, the finite element results should be presented to illustrate the applicability and accuracy of the proposed model. Therefore, to validate the described fiber finite element model, the results of three structural FRP-confined RPC columns tests by Malik and Foster (Malik and Foster, 2010) are used to compare the predictions from the finite element analyses. Additionally, for evaluating the performance of the proposed fiber element model, comparisons of the finite element analysis results and available three-dimensional (3D) finite element analyses data (Malik, 2007) are presented.

In the 3D finite element modeling (Malik, 2007), the behavior of the concrete was modeled by means of a plasticity model (Drucker-Prager) and a smeared crack model. The uniaxial nonlinear elasticity model with an appropriate elastic modulus and stress limits were used to model the FRP. The concrete and FRP were modelled by 20-noded brick elements and a cable element, respectively.

The tested columns considered (Malik and Foster, 2010) were cast with reactive powder concrete with or without steel fibers. The concrete column specimens wrapped with either two types of fiber-reinforced polymer wrapping included longitudinal and circumferential specimens. Details of the FRP type used for wrapping the columns and FRP properties are presented in Tabs. 1 and 2, respectively. 
Tab. 1 Details of FRP type of wrapping (Malik and Foster, 2010)

\begin{tabular}{ccccc}
\hline \multirow{2}{*}{ Laminate Structure } & \multicolumn{2}{c}{ Wrap Type 1 } & \multicolumn{2}{c}{ Wrap Type 2 } \\
\cline { 2 - 5 } Layer1 & Fiber Sheet & Wrap direction & Fiber Sheet & Wrap direction \\
Layer2 & CF120 & Longitudinal & CF350 & Longitudinal \\
Layer3 & CF120 & Longitudinal & CF350 & Longitudinal \\
Layer4 & CF120 & Circumferential & CF120 & Circumferential \\
\hline
\end{tabular}

Tab. 2 Mechanical properties of FRP (Malik and Foster, 2010)

\begin{tabular}{lll}
\hline FRP Type & CF120 & CF350 \\
\hline Tensile strength, $f^{\prime}{ }_{t f r p}$ & $3800 \mathrm{MPA}$ & $2650 \mathrm{MPA}$ \\
Modulus of Elasticity & $240 \mathrm{GPA}$ & $640 \mathrm{GPA}$ \\
Ultimate strain & $1.55 \%$ & $0.4 \%$ \\
\hline
\end{tabular}

Tab. 3 Material properties of the RPC and column details (Malik and Foster, 2010)

\begin{tabular}{cccccccc}
\hline Specimens & $\begin{array}{c}\tilde{n} \\
(\%)\end{array}$ & $\begin{array}{c}f_{m}^{\prime} \\
(\mathrm{MPA})\end{array}$ & $\begin{array}{c}f_{t}^{\prime} \\
(\mathrm{MPA})\end{array}$ & $\begin{array}{c}\mathrm{E} \\
(\mathrm{mm})\end{array}$ & $\begin{array}{c}\mathrm{D} \\
(\mathrm{mm})\end{array}$ & $\begin{array}{c}\mathrm{H} \\
(\mathrm{mm})\end{array}$ & $\begin{array}{c}\text { Wrap } \\
\text { type }\end{array}$ \\
\hline FC20-2 & 2 & 165 & 7.7 & 20 & 152.3 & 1056 & 2 \\
FC35-1 & 2 & 165 & 7.7 & 35 & 152.4 & 1058 & 1 \\
PC35-1 & 0.0 & 143 & 3.3 & 35 & 152.4 & 1055 & 1 \\
\hline
\end{tabular}

The confined RPC columns were tested under axial compressive loads with different eccentricities. Details of the column specimens are presented in Tab. 3 .

In Tab. $3, \tilde{n}$ is the volumetric percentage of the steel fibers; $f_{m}^{\prime}$ is the compressive strength of the RPC; E is the eccentricity of the load; D is the diameter of the concrete column cross-section; $\mathrm{H}$ is the height of the column; and $f_{t}^{\prime}$ is the tensile strength of the RPC. The comparisons of the nonlinear fiber finite element analysis results, the experimental test results, and the 3D finite element analysis results in terms of the axial load versus the lateral displacement are plotted in Figs. 6 to 8 .

As shown in Figs. 6 to 8, it can be observed that the present finite element model performs satisfactorily and accurately predicts the actual behavior of the FRP-confined RPC columns. Additionally, Tab. 4 contrasts the differences in the experimental results and the finite element analysis results in terms of peak axial loads and corresponding moments.

According to the comparisons (see Tab. 4), it can be seen that the results of the finite element analysis with OpenSees are consistent with the experimental test results. As shown in Figs. 6 to 8, the comparisons of results obtained from the 3D finite element model with the experimental data show a low degree of accuracy in terms of the lateral displacement.

Moreover, one should note that the mean of the ratio of the predicted load to the experimental load and its standard deviation are in a proper range. The analysis time is decreased in comparison with the analyses performed using the 3D finite element approach. Moreover, the accuracy of the analysis is increased in both the axial load and lateral displacement, which means that the fiber finite element model can be used to analyze the behavior of FRP-confined RPC columns. Hence, given the demonstrated accuracy of this model, the finite element model will be used to perform a numerical study of the behavior of FRP-confined RPC columns in a subsequent section of this paper.

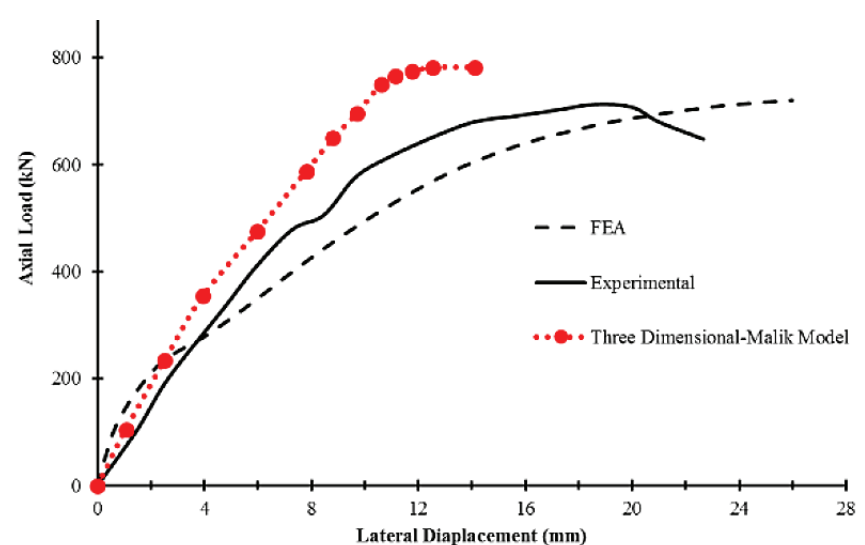

Fig. 6 Comparison of the results predicted with the test data for the FC35-1 column

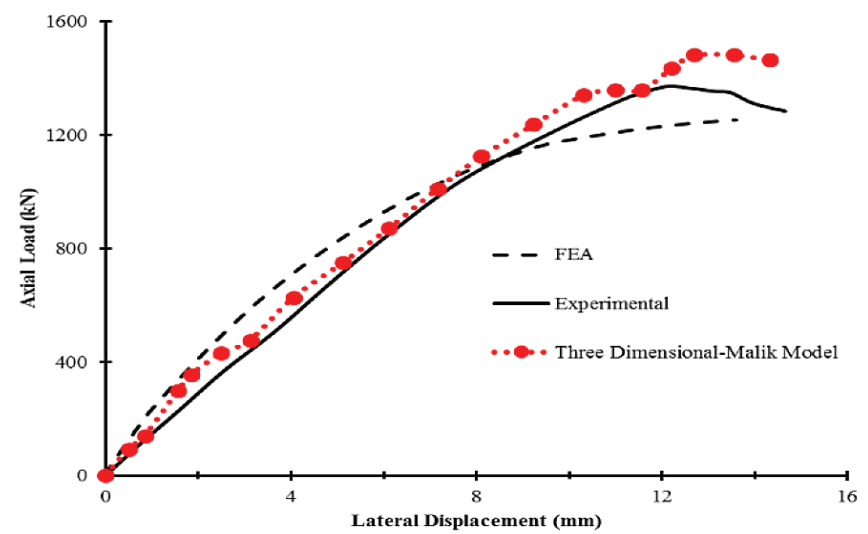

Fig. 7 Comparison of the results predicted with the test data for the FC20-2 column

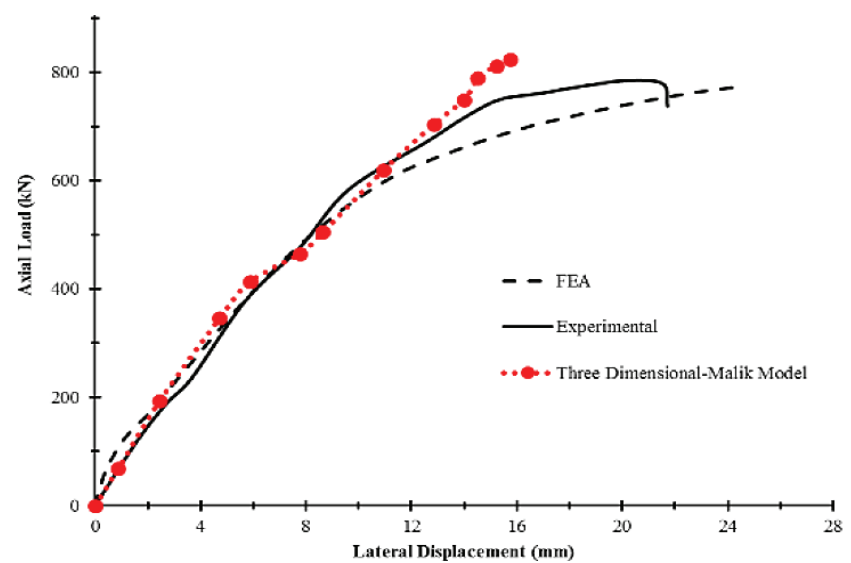

Fig. 8 Comparison of the results predicted with the test data for the PC35-1 column 
Tab. 4 Comparison of the test results with the finite element analysis results

\begin{tabular}{|c|c|c|c|c|c|c|}
\hline \multirow{2}{*}{ Column } & \multicolumn{3}{|c|}{ Peak Axial Load, $P_{u}(\mathrm{KN})$} & \multicolumn{3}{|c|}{ Moment at $P_{u}(\mathrm{KN}-\mathrm{m})$} \\
\hline & EXP & Fiber FEA & Fiber FEA/EXP & EXP & Fiber FEA & Fiber FEA/EXP \\
\hline PC35-1 & 773 & 772 & 1 & 43.4 & 42.53 & 0.98 \\
\hline FC20-2 & 1367 & 1253 & 0.92 & 47.0 & 46.11 & 0.98 \\
\hline FC35-1 & 714 & 720 & 0.99 & 38.9 & 45.23 & 1.16 \\
\hline \multicolumn{3}{|l|}{ Mean } & \multicolumn{3}{|l|}{0.97} & 1.04 \\
\hline \multicolumn{3}{|c|}{ Standard Deviation } & \multicolumn{3}{|l|}{0.04} & 0.1 \\
\hline
\end{tabular}

With the intention of only showing the validation of the finite element model used in this paper, the results corresponding to the three specimens are discussed. From the previous study (Abbassi, 2012), the details on the predicted results of the FRP-confined RPC columns can be found.

\section{DESCRIPTION OF THE COLUMNS AND THE LOADING}

As demonstrated in the previous section, the finite element model presented in this study can accurately predict the response of FRP-confined RPC columns. In this section, numerical work is conducted in order to study the behavior of reactive powder concrete columns confined with FRP under seismic loading.

The reactive powder concrete column that is considered in this study is a cantilever-type specimen, which is free at the top and fixed at the bottom. The concrete columns have a circular cross section. These circular confined RPC columns have the same height (3000 $\mathrm{mm}$ ). The RPC columns are wrapped with five layers of FRP. The thickness value of each layer is $0.1225 \mathrm{~mm}$. The FRP type used for wrapping the columns is CF120 (see Tab. 2). The analysis involves subjecting a finite element model to four ground motion records. Four different ground acceleration records from the Loma Prieta (USA 1989), Imperial Valley (USA 1940), Kobe (Japan 1995), and Tabas (Iran 1978) earthquakes were used to investigate the seismic performance of the FRP-confined RPC columns. In order to perform the

Tab. 5 Geometric and material properties of the subject columns

\begin{tabular}{llllll}
\hline Specimens & $\begin{array}{l}f_{m}^{\prime} \\
(\mathrm{MPA})\end{array}$ & $\begin{array}{l}f_{t}^{\prime}{ }_{\text {frp }} \\
(\mathrm{MPA})\end{array}$ & $\begin{array}{l}E_{f r p} \\
(\mathrm{GPA})\end{array}$ & $\begin{array}{l}\text { Diameter } \\
(\mathrm{mm})\end{array}$ & Earthquake \\
\hline C130-K & 130 & 3800 & 240 & 350 & Kobe \\
C140-K & 140 & 3800 & 240 & 350 & Kobe \\
C150-K & 150 & 3800 & 240 & 350 & Kobe \\
C130-I & 130 & 3800 & 240 & 350 & Imperial Valley \\
C140-I & 140 & 3800 & 240 & 350 & Imperial Valley \\
C150-I & 150 & 3800 & 240 & 350 & Imperial Valley \\
C130-L & 130 & 3800 & 240 & 350 & Loma Prieta \\
C140-L & 140 & 3800 & 240 & 350 & Loma Prieta \\
C150-L & 150 & 3800 & 240 & 350 & Loma Prieta \\
C130-T & 130 & 3800 & 240 & 350 & Tabas \\
C140-T & 140 & 3800 & 240 & 350 & Tabas \\
C150-T & 150 & 3800 & 240 & 350 & Tabas \\
\hline
\end{tabular}
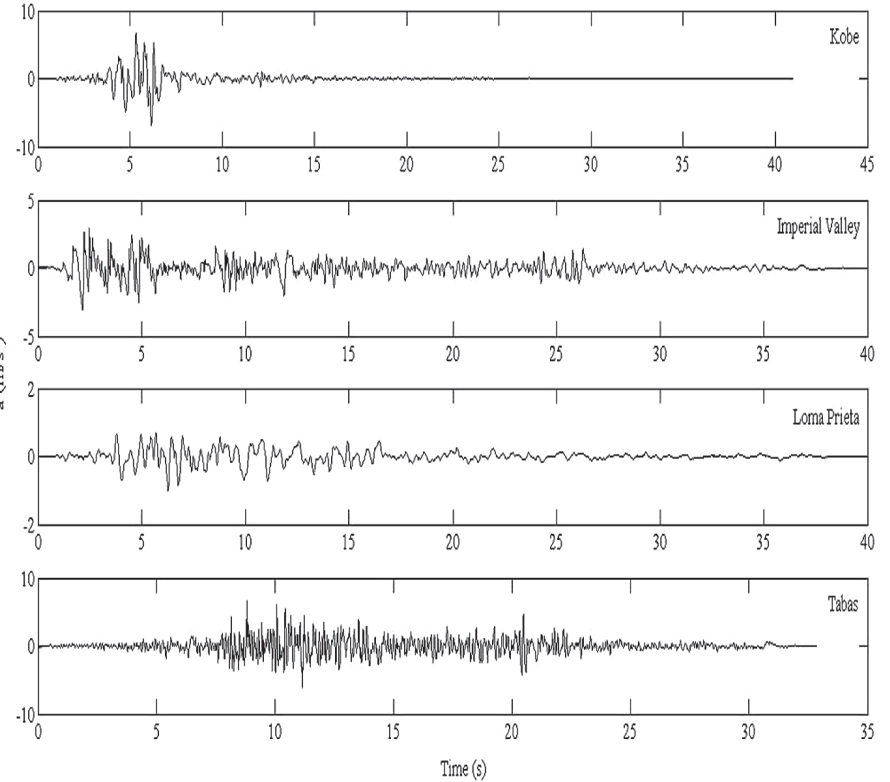

Fig. 9 Earthquake ground acceleration time histories

seismic analysis, the acceleration records were applied to the support of the columns. The ground acceleration time histories are shown in Fig. 9. Additionally, all of the columns were subjected to the same level of axial load.

Furthermore, to evaluate the effect of seismic loading on the response of the columns considered, three different concrete compressive strengths are used. In this regard, the concrete compressive strength varies among the three values of $130 \mathrm{MPa}, 140 \mathrm{MPa}$, and $150 \mathrm{MPa}$. To facilitate the study of the seismic behavior of the reactive powder concrete columns confined with FRP, the specimens are arranged in four groups. For group 1, the RPC columns considered are subjected to the Kobe earthquake, while the concrete compressive strength varies among three values, i.e., $130 \mathrm{MPa}, 140 \mathrm{MPa}$, and 150 MPa. Groups 2-4 are similar to group 1, except that the columns are subjected to the Imperial Valley, Loma Prieta and Tabas earthquakes, respectively. The detailed geometric and material properties of these columns are given in Tab. 5 .

\section{RESULTS AND DISCUSSIONS}

\subsection{Specimens of group 1}

The results of the nonlinear finite element analysis of the lateral load versus the lateral displacement for the specimens under the Kobe earthquake are plotted in Figs. 10 to 12. 


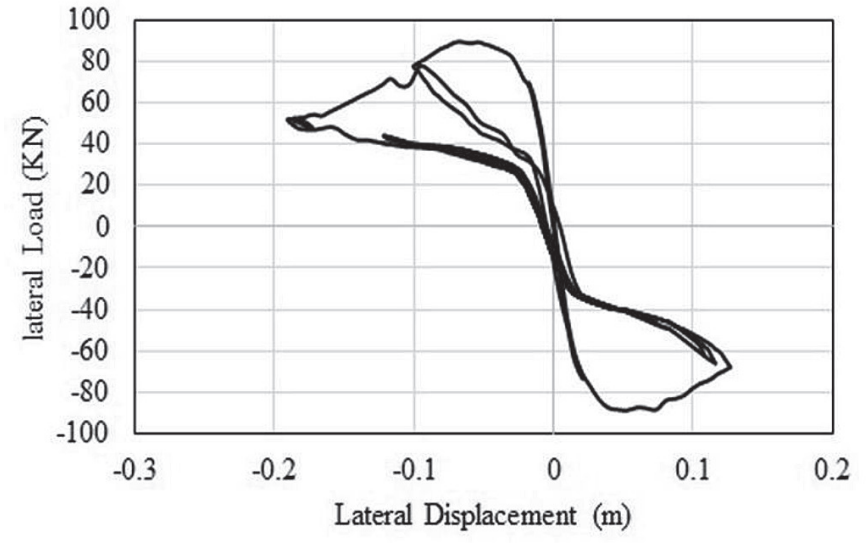

Fig. 10 Hysteretic response of C130-K

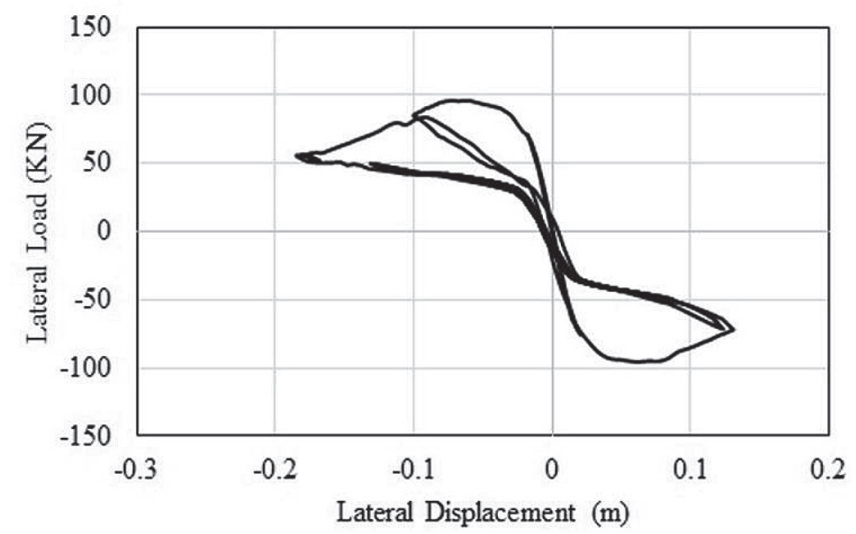

Fig. 11 Hysteretic response of C140-K

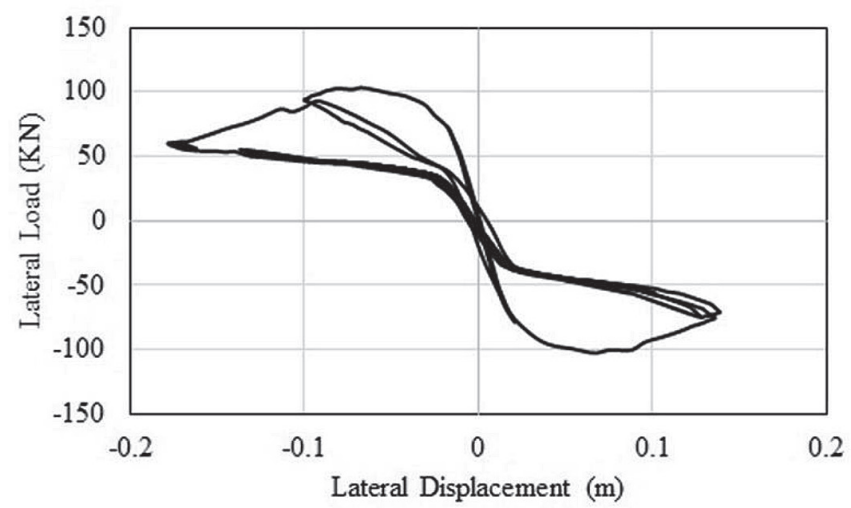

Fig. 12 Hysteretic response of $C 150-K$

As illustrated in Figs. 10 to 12, when the concrete's compressive strength is increased, an increase in the lateral load capacity is obtained; however, the displacement at the top of the columns is not changed significantly. As an example, the maximum lateral load capacity of the $\mathrm{C} 130-\mathrm{K}$ is $89.4 \mathrm{KN}$, which increases to $96.1 \mathrm{KN}$ when the concrete's compressive strength is changed to 140 MPA, i.e., an improvement of $8 \%$. In this context, the maximum lateral load capacity is increased by $7 \%$ for $\mathrm{C} 150-\mathrm{K}$ in comparison with $\mathrm{C} 140-\mathrm{K}$. Fig. 10 shows that the maximum lateral displacement obtained for the $\mathrm{C} 130-\mathrm{K}$ is equal to $19.04 \mathrm{~cm}$. The utilization of the reactive powder concrete with a compressive strength equal to $140 \mathrm{MPA}$ and $150 \mathrm{MPA}$ causes a decrease in the maximum lateral displacement of about $3 \%$ and $6 \%$ respectively. In this regard, although the results showed that the variation in the maximum lateral displacement is a gradual pro-

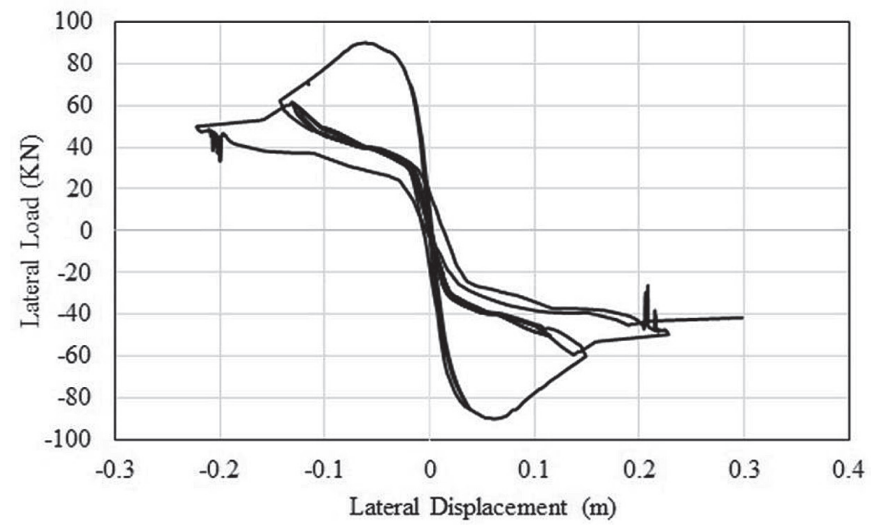

Fig. 13 Load-displacement hysteresis loops for C130-I

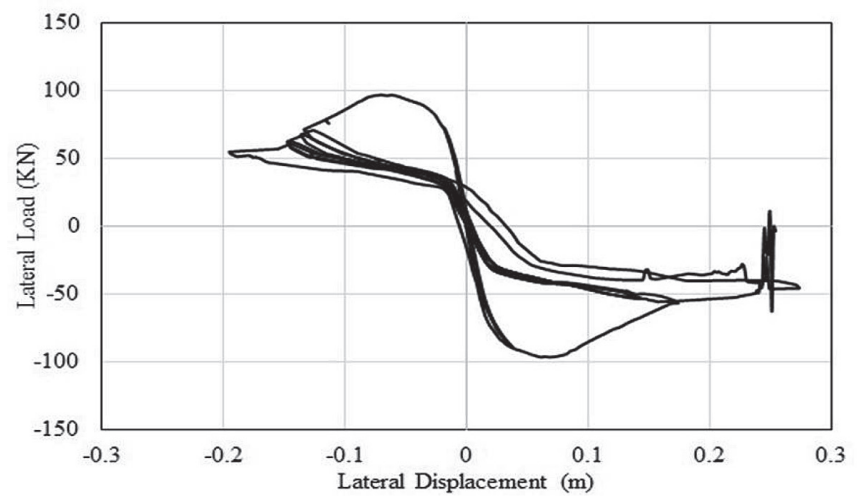

Fig. 14 Load-displacement hysteresis loops for C140-I

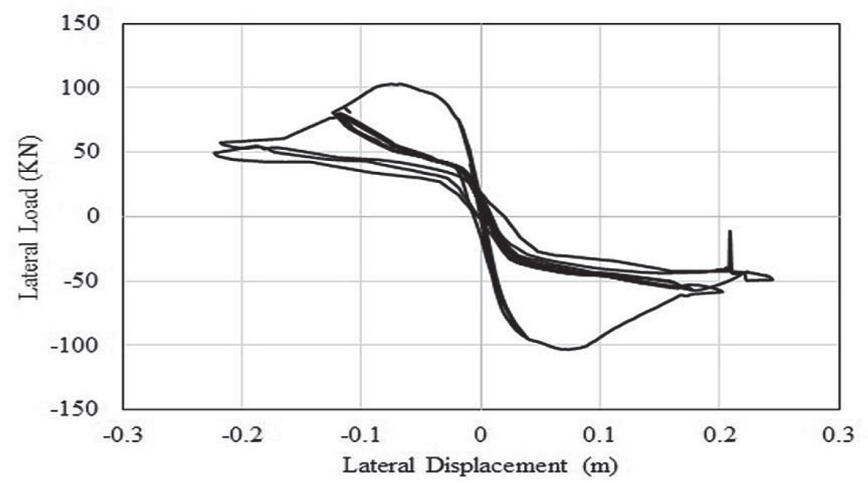

Fig. 15 Load-displacement hysteresis loops for C150-I

cess and can be modeled by a straight line with a negative slope, these variations are insignificant.

\subsection{Specimens of group 2}

The lateral load versus the lateral displacement (measured at the top of the columns) curves predicted by the presented fiber model that was subjected to the Imperial Valley ground motion are shown in Figs. 13 to 15.

As can be seen from Figs. 13 to 15, the use of concrete with a higher compressive strength increases the lateral load capacity of the columns. As shown in Fig. 13, the maximum lateral displacement of C130-I is $29.79 \mathrm{~cm}$. Additionally, the value of the maximum lateral 


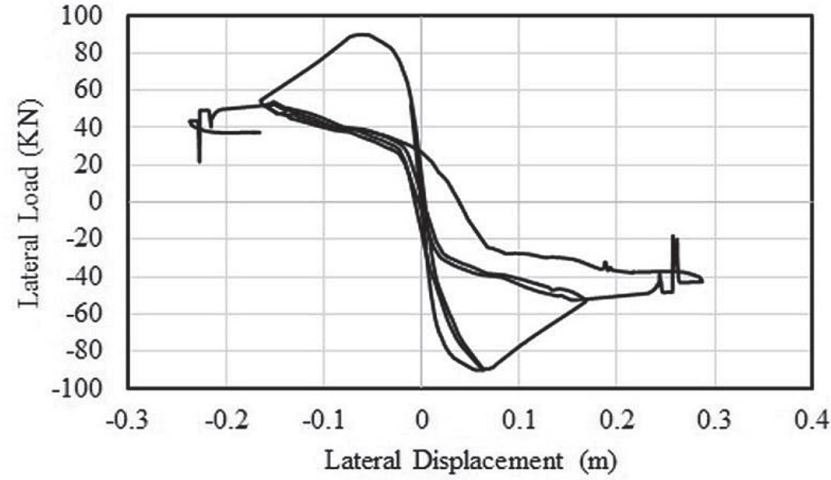

Fig. 16 Lateral load-displacement for C130-L specimen

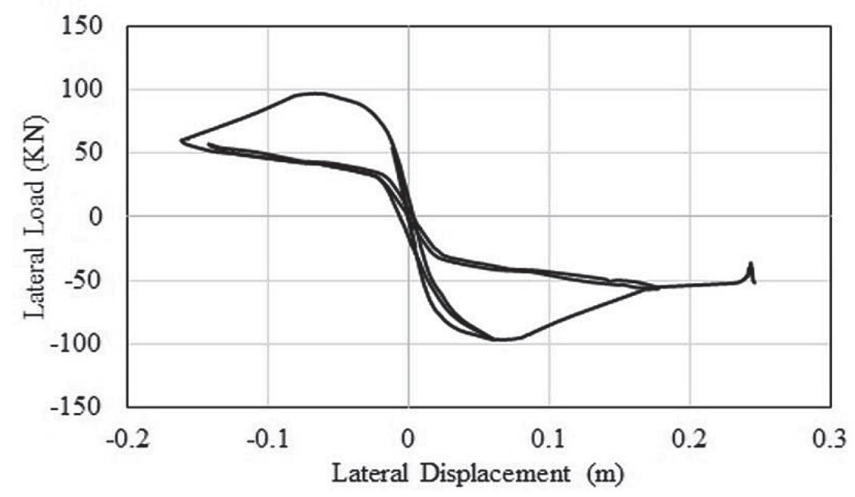

Fig. 17 Lateral load-displacement for C140-L specimen

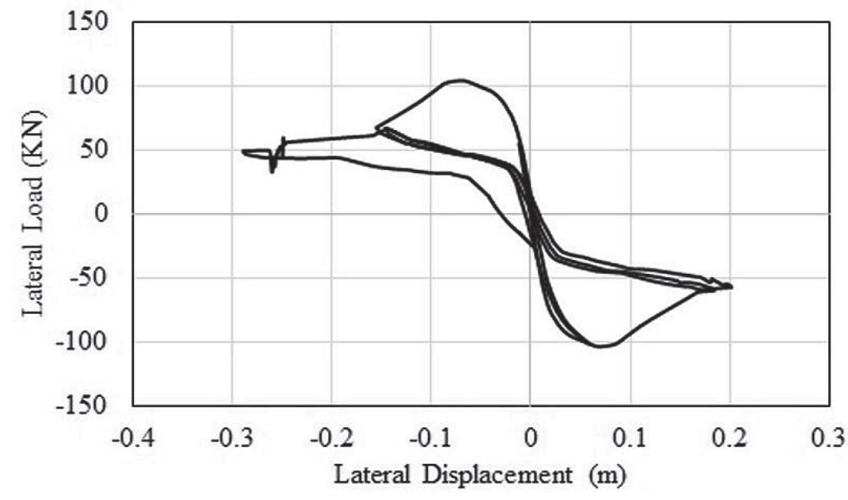

Fig. 18 Lateral load-displacement for C150-L specimen

displacement of C140-I is estimated to be $27.36 \mathrm{~cm}$. Compared to C130-I, the maximum lateral displacement of C140-I is decreased by $18 \%$. In this regard, increasing the concrete compressive strength from 140 MPA to 150 MPA decreases the value of the maximum lateral displacement of the confined RPC columns. It should be noted that although the maximum lateral displacement capacity at the top of the columns slightly decreased, the response of the considered columns subjected to the Imperial Valley earthquake demonstrated a good degree of ductility.

\subsection{Specimens of group 3}

The results of the lateral load versus the lateral displacement at the top of the columns under the Loma Prieta earthquake are illustrated in Figs. 16 to 18.

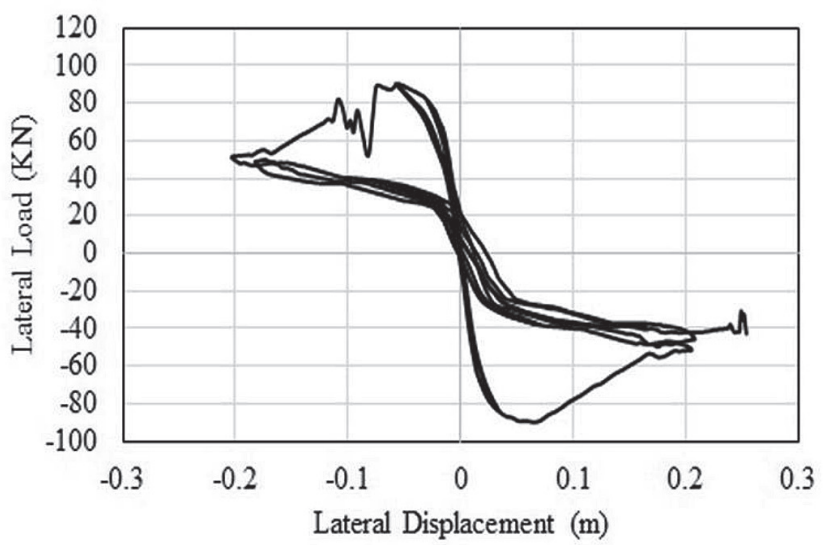

Fig. 19 Lateral cyclic load-displacement of C130-T

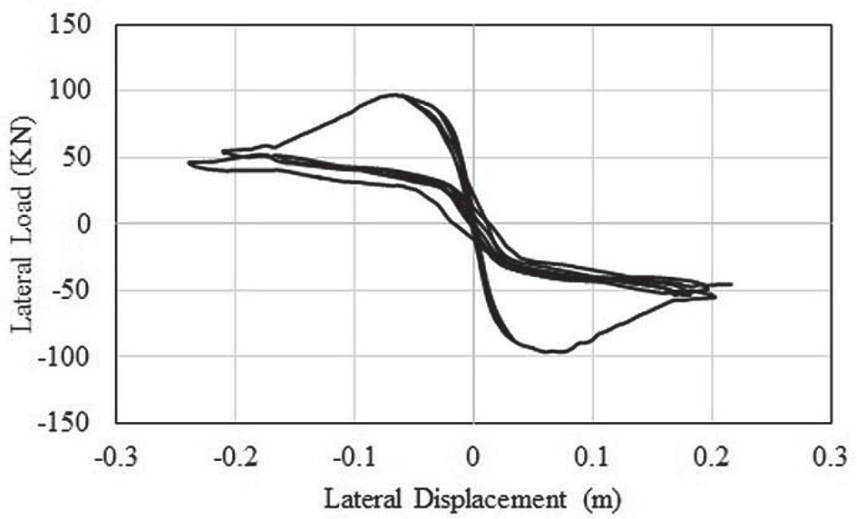

Fig. 20 Lateral cyclic load-displacement of C140-T

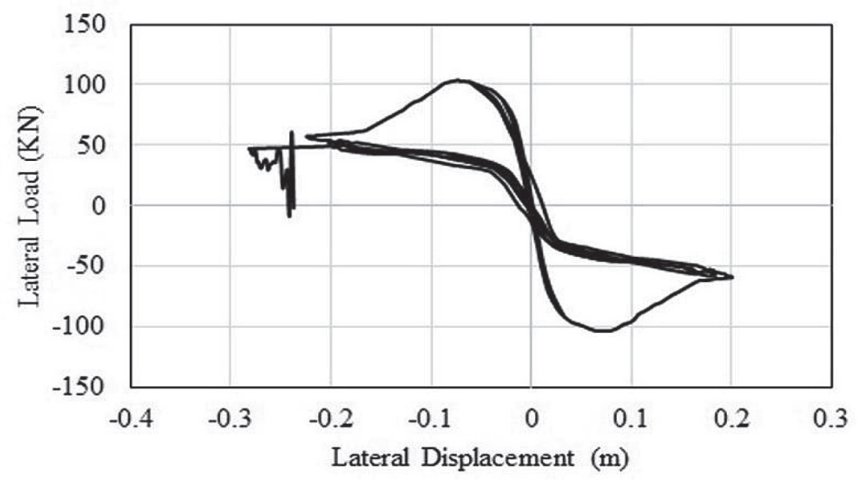

Fig. 21 Lateral cyclic load-displacement of C150-T

It is evident from Figs. 16 to 18 that the response of a circular FRP-confined reactive powder concrete column is dependent on the compressive strength of concrete. The load capacity of the confined RPC columns gradually increases as the concrete's compressive strength increases (see Figs. 16 to 18). In this regard, even though increasing the concrete's compressive strength increases the lateral load capacity of the confined column, the maximum lateral displacement of the confined columns due to the enhancement of the concrete's compressive strength is not continually increased. As illustrated in Figs. 16 and 17, when the concrete compressive strength of the reactive powder concrete increases by $8 \%$ (increasing the concrete's compressive strength from $130 \mathrm{MPA}$ to $140 \mathrm{MPA}$ ), the lateral displacement capacity of the FRP-confined RPC columns is decreased. Similarly, when the concrete's compressive strength increases by $7 \%$ (increasing the concrete's compressive strength from 140 MPA to 150 MPA), the lateral displacement is increased. 


\subsection{Specimens of group 4}

The hysteresis lateral load and displacement curves obtained from the columns subjected to the Tabas earthquake are shown in Figs. 19 to 21.

From Figs. 19 to 21, it can be concluded that the load-carrying capacity is increased when the concrete's compressive strength is increased from $130 \mathrm{MPA}$ to $140 \mathrm{MPA}$ and from $140 \mathrm{MPA}$ to 150 MPA. In this context, in the cases of C150-T and C140-T, it can be seen that the predicted maximum lateral load increased by $15 \%$ and $8 \%$ as compared to the C130-I, respectively. From a displacement of view, as the reactive powder concrete's compressive strength is increased from $130 \mathrm{MPA}$ to $140 \mathrm{MPA}$, the displacement at the top of the columns is decreased by $6 \%$. In a like manner, the quantity of the maximum lateral displacement for $\mathrm{C} 150-\mathrm{T}$ is $12 \%$ more than that for C130-T.

Based on the current study, it can be concluded that the confined RPC columns analyzed have an acceptable seismic performance. It should be noted that the specimens with a higher concrete strength have a greater lateral load capacity than those with a lower concrete strength. Additionally, the confined reactive powder concrete columns showed reasonable lateral strength and ductility.

\section{CONCLUSION}

In this paper, the seismic performance of reactive powder concrete columns confined with FRP was numerically investigated. In this regard, the nonlinear finite element model based on fiber finite element methodology was used. The FRP-confined RPC columns was modeled by two noded nonlinear beam-column elements. The nonlinear behavior of RPC in compression was simulated by the modified Kent and Park model. The tensile behavior of the RPC was modeled in two regions, i.e., the linear ascending stress region up to the peak tensile stress and the linear descending region that occurs after the peak tensile stress. Additionally, it was assumed that the behavior of FRP in tension and compression is linear, elastic, and brittle. The finite element analyses were performed using OpenSees software. The response predictions of the numerical model for the RPC columns were validated with the experimental responses. In order to study the behavior of the columns considered, the fiber model presented was subjected to seismic excitations. Four earthquake records with different peak ground accelerations were applied to study the seismic performance of the columns. To evaluate the effect of the RPC compressive strength on the response of the columns, three different concrete compressive strengths were considered. Based on the results of the finite element analyses presented in this paper, the following conclusions may be drawn:

1. The FRP-confined reactive powder concrete columns analyzed show a satisfactory seismic response.

2. The load capacity (maximum lateral load) is increased gradually while the concrete's compressive strength is increased.

3. The hysteretic performance of the FRP-confined RPC columns analyzed herein demonstrated good ductility characteristics.

4. The proposed model can be used in engineering projects for the seismic analysis of reactive powder concrete columns confined with FRP because of the low computational efforts and satisfactory predictions (between the numerical and experimental data).

Although the present work confirmed that the seismic behavior of FRP-confined RPC columns is reasonable because of the acceptable ductility and load capacity, further investigations are needed to use the columns considered in engineering projects because the effects of other structural factors are not obvious; these are the subject of on-going investigations. 


\section{REFERENCES}

Abbassi, M. (2012) Nonlinear finite element modelling of reactive powder concrete columns retrofitted by carbon fiber reinforced polymer. MSc Thesis, Civil Engineering Dept, University of Kurdistan, Sanandaj, Iran.

Abbassi, M. - Dabbagh, H. (2014) Behavior of FRP-confined reactive powder concrete columns under eccentric loading. Journal of Rehabilitation in Civil Engineering 2(1), pp. 46-64.

Abdelouahed, T. (2006) Improved Theoretical solution for interfacial stresses in concrete beams strengthened with FRP plate. International Journal of Solids and Structures 43, pp. 4154-4174.

Al-Amery, R. - Al-Mahaidi, R. (2006) Numerical analysis of multilayered CFRP retrofitted $R C$ beams with partial interaction. Composite Structures 75, pp. 479-488.

Aïtcin, P. C. (2000) Cements of yesterday and today concrete of tomorrow. Cement and Concrete Research 30(9), pp. 1349-1359.

Bouchelaghem, H. - Bezazi, A. - Scarpa, F. (2011) Compressive behaviour of concrete cylindrical FRP-confined columns subjected to a new sequential loading technique. Composites Part B: Engineering 42, pp. 1987-1993.

Coronado, C. A. - Lopez, M. M. (2006) Sensitivity analysis of reinforced concrete beams strengthened with FRP laminates. Cement and Concrete Composites 28, pp. 102-114.

Dowd, W. M. - Dauriac, C. E. - Adeline, R. (1999) Reactive powder concrete for bridge construction. Proceeding of the 5th ASCE Materials Engineering Congress, Cincinnati, USA

El-Hacha, R. - Abdelrahman, K. (2013) Slenderness effect of circular concrete specimens confined with SFRP sheets. Composites Part B: Engineering 44, pp. 152-166.

Feng, D. C. - Xu, J. (2018) An efficient fiber beam-column element considering flexure-shear interaction and anchorage bond-slip effect for cyclic analysis of RC structures. Bulletin of Earthquake Engineering 16, pp. 5425-5452.

GangaRao, H. V. S. - Taly, N. - Vijay, P. V. (2007) Reinforced concrete design with FRP composites. Englewood Cliffs, CRC Press, USA.

Guidi, G. (2011) Displacement capacity of load-bearing masonry as a basis for seismic design. Ph.D. Thesis, Civil Engineering Dept, University of Toronto, Toronto, Canada.

Ho, J. C. M. - Lam, J. Y. K. - Kwan, A. K. H. (2010) Effectiveness of adding confinement for ductility improvement of high-strength concrete columns. Engineering Structures 32, pp. 714-725.

Jiang, L. - Usmani, A. (2018) Computational performance of beam-column elements in modelling structural members subjected to localised fire. Engineering Structures 156, pp. 490-502.

Jiang, J. F. - Wu, Y. F. (2012) Identification of material parameters for drucker-prager plasticity model for FRP confined circular concrete columns. International Journal of Solids and Structures 49, pp. 445-456.
Lee, I. (2002) Complete stress-strain characteristics of high performance concrete. Ph.D. thesis, Civil Engineering Dept, New Jersey Institute of Technology, New Jersey, USA.

Ma, R. - Xiao, Y. (1999) Seismic retrofit and repair of circular bridge columns with advanced composite materials. Earthquake Spectra 15(4), pp. 747-764.

Malik, A. R. (2007) An investigation into the behavior of reactive powder concrete columns. Ph.D. thesis, School of Civil and Environmental Engineering, The university of New South Wales, Sydney, Australia.

Malik, A. R. - Foster, S. J. (2010) Carbon fiber-reinforced polymer confined reactive powder concrete columns-experimental investigation. ACI Structural Journal 7(3), pp. 263-271.

Mazzoni, S. - McKenna, F. - Scott, M. H. - Fenves, G. L. (2007) OpenSees command language manual. Pacific Earthquake Engineering Research Center, University of California, Berkeley, USA.

Morin, V. - Cohen-Tenoudji, F. - Feylessoufi, A. (2002) Evolution of the capillary network in a reactive powder concrete during hydration process. Cement and Concrete Research 32(12), pp. 1907-1914.

Ozbakkaloglu, T. - Saatcioglu, M. (2006) Seismic behavior of highstrength concrete columns confined by fiber-reinforced polymer tubes. Journal of Composites for Construction ASCE 10(6), pp. 538-549.

Purba, B. K. - Mufti, A. A. (1999) Investigation of the behavior of circular concrete columns reinforced with carbon fiber reinforced polymer (CFRP) jackets. Canadian Journal of Civil Engineering 26(5), pp. 590-6.

Spacone, E. - Filippou, F.C. - Taucer, F. F. (1996) Fiber beam-column model for non-linear analysis of RC frames: part I. formulation. Earthquake Engineering and Structural Dynamics 25, pp. 711-725.

Xiao, Y. (1997) Seismic retrofit of RC circular columns using prefabricated composite jacketing. Journal of Structural Engineering ASCE 123(10), pp. 1357-64.

Yalcin, C. - Saatcioglu, M. (2000) Inelastic analysis of reinforced concrete columns. Computers and Structures 77, pp. 539-555.

Ye, L. P. - Zhang, K. - Zhao, S. H. - Feng, P. (2003) Experimental study on seismic strengthening of $R C$ columns with wrapped CFRP sheets. Construction and Building Materials 17, pp. 499506.

Yu, T. - Teng, J. G. - Wong, Y. L. - Dong, S. L. (2010) Finite element modeling of confined concrete-I: drucker-prager type plasticity model. Engineering Structures 32(3), pp. 665-679. 